\title{
Group Decision Support Systems for Emergency Management and Resilience: CoastalProtectSIM
}

\author{
Xiaoyi Zhao \\ University at Albany \\ xzhao6@albany.edu \\ Eliot Rich \\ University at Albany \\ erich2@albany.edu
}

\author{
Yumei Chen \\ Jinan University \\ tchenym@jnu.edu.cn \\ Michael Deegan \\ U.S. Army Corps of Engineers \\ Institute for Water Resources \\ mdeegan@yahoo.com
}

\author{
Mingyoung $\mathrm{Ku}$ \\ University at Albany \\ Minyku5@gamil.com \\ Luis F. Luna-Reyes \\ University at Albany \\ 1luna-reyes@albany.edu
}

\begin{abstract}
This paper introduces the concept of Group Decision Support Systems (GDSS) as a tool to support emergency management in coastal cities. As an illustration of the potential value of GDSS, we discuss the use of CoastalProtectSIM, a simulation model that can be a valuable GDSS tool, particularly in the mitigation stages of the emergency management cycle. We present preliminary results from the use of the simulation environment in a graduate course. We finish the paper by presenting our experience as a framework for building more efficient and secure emergency management systems through the use of GDSS.
\end{abstract}

\section{Introduction}

A city's resilience is its capability to respond rapidly to unforeseen change, even when faced with chaotic disruption. It is the ability to bounce back and move forward with speed, grace, determination and precision [3]. Resilience is a quality covering the complete emergency management cycle, from the mitigation stages to recovery. Local resiliency with regard to disasters means that a locale is able to withstand an extreme natural event without suffering devastating losses, damage, diminished productivity, or quality of life and without a large amount of assistance from outside the community [19]. A resilient city is a sustainable network of physical systems and human communities [14]. A city without resilient physical systems will be extremely vulnerable. Thus, cities around the world are establishing emergency response centers as infrastructures to coordinate responses to emergency. Although data and technology infrastructures are critical components in building resiliency, collaboration and decision-making when anticipating and during incidents becomes also another critical factor to support the cities' recovery and resumption of sustainable activity.

In this paper we explore our experiments to employ Group Decision Support Systems (GDSS) and facilitated learning to emergency planning and resilient cities. We posit that GDSS provides methods and processes needed to use technology in facilitating problem definition and decision making, but also provide a milieu to build relationships and trust among stakeholders, which constitute prerequisites to effective collaborations $[18,26]$. Given the diversity of natural hazards, we focus on how to improve the resilience of coastal cities to storms and typhoons or hurricanes.

To accomplish this purpose, this paper is organized in five sections including this introduction. The second section includes a review of the literature in GDSS and emergency management to introduce main concepts in both areas of research. Section three includes a description of CoastalProtectSIM, a simulation model created to be used as a tool to facilitate group decision support. The fourth section introduces preliminary use of CoastalProtectSIM in the context of a classroom in a school of Public Administration, as well as some preliminary results of its use in the classroom environment. We finish the paper by discussing ways GDSS can complement planning and action across the emergency management cycle.

\section{Literature Review 2.1. Emergency Management}

Emergency and disaster management are facilitated through plans which communities reduce vulnerability 
to hazards and cope with disasters [7]. Unlike other challenges facing society, such as crime and pollution, it is impossible to control many natural disasters because they occur exogenously. Therefore, it is significant and beneficial to implement effective disaster damage reduction activities (i.e., mitigation) in the process of emergency management. Failure to create a plan could lead to damage to assets, human mortality, and lost revenue [13].

In 1979, the US National Governor's Association (NGA) provided a broad framework for emergency management, identifying four phases of emergency management: mitigation, preparedness, response and recovery. Mitigation aims to reduce the chance of an emergency happening, or to minimize the effects of unavoidable emergencies. Buying homeowner's flood and fire insurance is a mitigation activity. Preparedness refers to plans and preparation before emergency occurs, made to save lives and to help response and rescue operations. Evacuation plans and stocking food and water are both examples of preparedness. During an emergency, response is putting the preparedness plans into action. Appropriate response is necessary and helpful to save lives and prevent further property damage. Seeking shelter from a tornado or turning off gas valves in an earthquake are both response activities. After an emergency, recovery activities, such as getting financial assistance for repairs, will be taken to help return to a normal or an even safer situation [9].

When facing emergencies, society and government must respond quickly and accurately in resource deployment and immediate actions and tactics. In the United States, emergency management (EM) functions are managed according to the principles of the National Incident Management System (NIMS), which is a preparedness and response management model based on the Incident Command System (ICS) [4]. Emergency response actions and decisions must be made on the basis of real-time data gathering. Data usually come from government agencies, as well as private companies, such as power, water and gas supply organizations. After September 11, 2001, the US government also established the National Information Exchange Model (NIEM), which provides an information sharing and data exchange platform using a community-driven and standards-based approach. All 50 states and the majority of federal agencies are using (at varying levels of maturity), or considering using NIEM [8].

\subsection{Group Decision Support Systems (GDSS) and Emergency Management}

EM requires collaboration of different stakeholders and decision makers, either to prepare to respond to the emergency or to make decisions and allocate resources during the emergency itself. Our review also suggests the need of having the appropriate information to support those processes. GDSS are interactive computer-based systems that help to generate ideas and actions, choose alternatives and negotiate solutions by a group of decision makers working together. They aim to take advantage of the effectiveness of group decision through interactively exchanging ideas, opinions and preference among group members and computer system [6]. Different from the conventional view of decision support systems, which are intended to support individual decision-makers, GDSS involve a group of people spending time discussing and structuring problems and potential solutions [11]. Group decision support combines technology and process support, including so-called "soft systems" approaches such as Soft Systems Methodology or Strategic Assumptions Surfacing and Testing [1, 21].

Hardware (input/output device), software (user interface), people (group member and facilitator) and procedures (methods used in meetings) are the four components of GDSS [11] (see Figure 1). In terms of hardware and software, GDSS offer various levels of computational support in order to remove communication obstacles (level 1), provide techniques for structuring decision analysis (level 2) and systematically directing the pattern, timing, or content of the discussion (level 3) [27]. It adds value to collaborative problem solving by providing tools for parallel communication, anonymous interaction and automatic recording of discussions [12]. In terms of people and processes, GDSS researchers have identified three main tasks involving different cognitive processes: eliciting information (brainstorming or divergent thinking), exploring courses of action (convergent thinking), and evaluating situations (convergent thinking) [27]. Both NIMS and NIEM constitute examples of standards and policy requirements which may be instrumentalized with GDSS when used by the right stakeholders (people), and following appropriate processes.

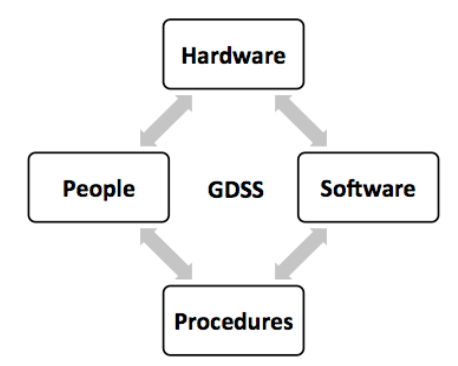
Figure 1: Four components of a group
decision support system 
One specific type of GDSS-decision conferencesconstitute an instance of computer-supported meetings where data and models are used by decision makers following a specific facilitation plan [20, 24]. In terms of modeling, the approach can use a variety of modeling techniques, including multi-attribute decision modeling, judgment analysis, resource allocation and simulation [24]. Facilitation relies on teamwork [23], and a series of scripts, which are "planned and rehearsed routines for accomplishing sub-goals in the course of group model building workshop" [2].

Previous research suggests that GDSS might be used in the context of emergency management. For example, Deng and Chen designed a GDSS framework that included main functions of a system including querying system and emergency assessment tools, which provide information services for emergency management and decision support in the area of health support [6].

Janža describes a water resource management system using GDSS to identify options that might mitigate pollution of groundwater. The system gathers data from a monitoring network, and using numerical modeling techniques and expert knowledge, it supports the detection of pollution in the groundwater, the simulation of pollution propagation as well as decision making. The system provides an important foundation for proactive water resource management [15].

Finally, $\mathrm{Yu}$ and Lai proposed a distance-based group decision-making (GDM) methodology to solve unconventional multi-person multi-criteria emergency decision-making problems. Using a numerical example and practical case, they demonstrate that GDM methodology can improve decision making objectivity and emergency management effectiveness [28].

\section{CoastalProtectSIM as an Example of GDSS to Emergency Management}

In this section of the document, we introduce CoastalProtectSIM, a simulation-based environment that has been developed to support community-based GDSS activities led by the U.S. Army Corps of Engineers' Mississippi Coastal Improvement Program [16]. The simulation environment was developed to better understand emergency mitigation in the face of weather-related storm surges in the US coast.

Ten years after Hurricane Katrina devastated the US Gulf Coast, we are still examining the effectiveness of the response and recovery efforts and their influence on resilience development. A review of the patterns of response infrastructure have informed and improved the ability to prepare for future calamities, but also the challenge of creating informed plans at operational detail [25]. The extent of this disaster taught planners about the role of community infrastructure for social recovery [22]. Still, the efforts for recovery do not ensure or even reduce the scope of future disruptions. For example, the economic recovery of New Orleans since the storm remains dependent upon low-paying jobs and tourism, and therefore vulnerable to future storms and subsequent dislocation and damage [17].

CoastalProtectSIM builds on another set of lessons from the Katrina disaster. There were differences in the way contiguous Gulf communities were affected by the same storm. Areas that had preserved natural barriers (wetlands and swamps) and invested in built protection were better able to weather storm surges than those that had encouraged high levels of coastal development. Unlike recovery efforts, the differences in development are the result of decades of decisions prior to the event, where the preservation of natural resilience competed against economic needs.

Development decisions are complex and contentious. Communities attempting to ensure their resilience against uncertain storm and weather conditions are making decisions replete with competing concerns from stakeholders that interact and conflict. Development of coastal land into homes, businesses, and other income generating properties supports the economic health of the location. Development can also increase the demand for additional protection, while reducing the protection that comes from coastal marshes and other natural barriers. Building new barriers to restore this protection takes time and requires funding, which may come from taxes on developed land.

CoastalProtectSIM examines the effects of development, planning, perceptions and weather uncertainty in a feedback rich structure [5]. CoastalProtectSIM captures elements of complexity within the problem context of a hypothetical coastal community: (1) delays in constructing coastal protection; (2) cost sharing challenges for construction and annual maintenance; (3) impacts of coastal land development on natural barriers; and (4) the timing of benefits and costs in net present value calculations for long range coastal flood risk planning. An optional global warming scenario is built into the model that allows for the amplification of the storm surges based on severity of storms and sea level rise. CoastalProtectSIM allows the decision maker to determine whether the long term benefits of resiliency are worth the investment of short and intermediate term mitigation measures. The time span for the model is 40 years to allow for long term and short term tradeoffs to be explored. 


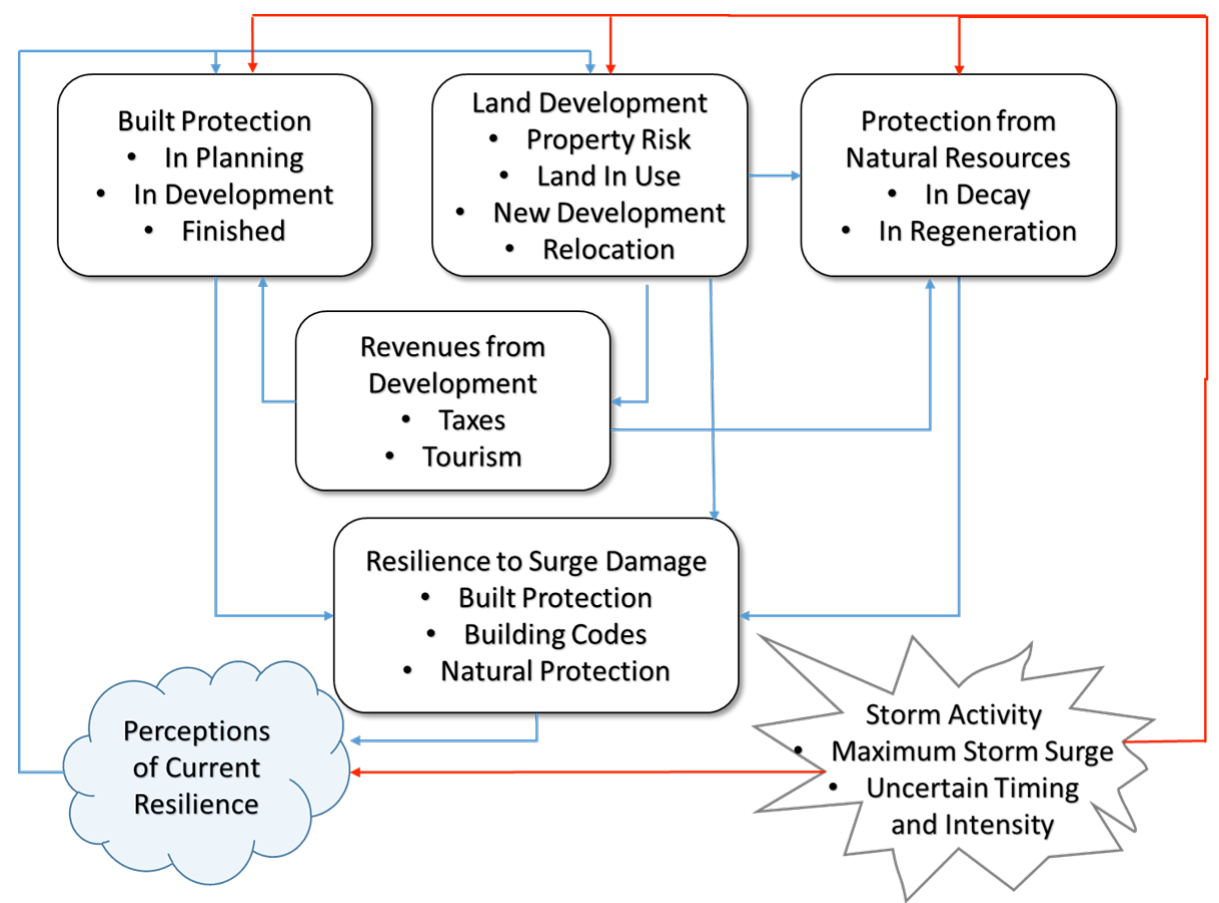

Figure 2: Main Components in CoastalProtectSIM

Figure 2 captures the essential elements of CoastalProtectSIM; coastal storm planning: Starting at the lower left corner of the exhibit, we assume that a community has a set of perceptions about the adequacy of the resilience of the community against the arrival of annual storms of unknown timing and intensity. These perceptions lead to pressures to promote some mix of built protection and land development (blue lines). Protections have a long lead time to complete, as they are complex engineering activities. Land development occurs faster, but may also be influenced by local policies and codes. Policy changes may only affect new development, as existing structures are often exempted from the need to retrofit. Development also promotes economic growth and revenue generation, which can then be used to pay for additional built and natural protection. Land development also influences the strength and capacity of the remaining natural resources and their effects on surge mitigation.

Built protection, careful land development and natural resources all contribute to the long-term resilience of a community to storms, but they may not be adequate in the face of uncommon and uncertain high-impact weather events (red lines). In addition, the infrequency of severe events may bias perceptions about the adequacy of past decisions resilience and the need to continue investment. Thus decision-makers may not have a complete understanding of how their short-term decisions regarding investments and planning may have poor longer term effects.
Using CoastalProtectSim in the context of GDSS, participants can simulate how changes in priorities among development, built protection and preservation interact over time and different assumptions. Users can consider different build protection heights and building codes, changes in storm patterns, and investments in relocation and buyout policies. Through simulation of a generic problem, conversations regarding these tradeoffs can be launched reflecting the conditions within unique local communities, resulting in better and more inclusive decisions.

\section{Preliminary Experiences using CoastalProtectSIM}

In this section of the paper, we report preliminary experiences of group decision making with CoastalProtectSIM. These experiences were in the context of three Master of Public Administration (MPA) classes at a U.S. university in the 2013-2014 academic year. The three classes were different sections of the same course that aimed to teach students about the use of data and models to tackle complex public policy problems. In total, 70 students from the three classes participated in the experience. Most participants (90\%) were graduate students who held a bachelor degree, and $10 \%$ were senior undergraduate students. Students participated in a 10 -week class exercise (i.e. 30 hours) involving the use of GDSS tools and techniques. 
The class exercise consisted of three distinct but closely connected stages: (1) pre-simulation (3 weeks), (2) introduction to the simulation and individual-group exercise (5 weeks), and (3) group decision making with the simulation ( 2 weeks). In the pre-simulation stage, we introduced the participants to a case, the Pointe Claire Coastal Protection Planning Exercise (PCCPPE), which is paired with CoastalProtectSIM (for more information about the case, see [16]). The case study was developed as a classroom activity as well as training tool to improve learners' analytical thinking and problem-solving competency [16]. The first four weeks of our experiment were dedicated to help students grasp the decision-making context, preparing an urban community against possible future natural disasters, and to teach the complexity of group decision making, including decision making under uncertainty to prepare for/against unexpected future events. We introduced theoretical concepts and models of analytic decision making in the domain of public policy decision making, complex systems, and systems thinking.

The second stage of the class exercise involved learning about GDSS using CoastalProtectSIM as the main tool (see Figure 3). After an introductory class about simulation environments, students had 3 weeks of hands-on exercises with CoastalProtectSIM, and one week of an actual Decision Conference -using Group Model Building techniques - to give participants the opportunity to learn about stakeholders in the community so that they could grasp the social environment of the case and immerse themselves into their role in the case study, the policy analyst who supports the community.

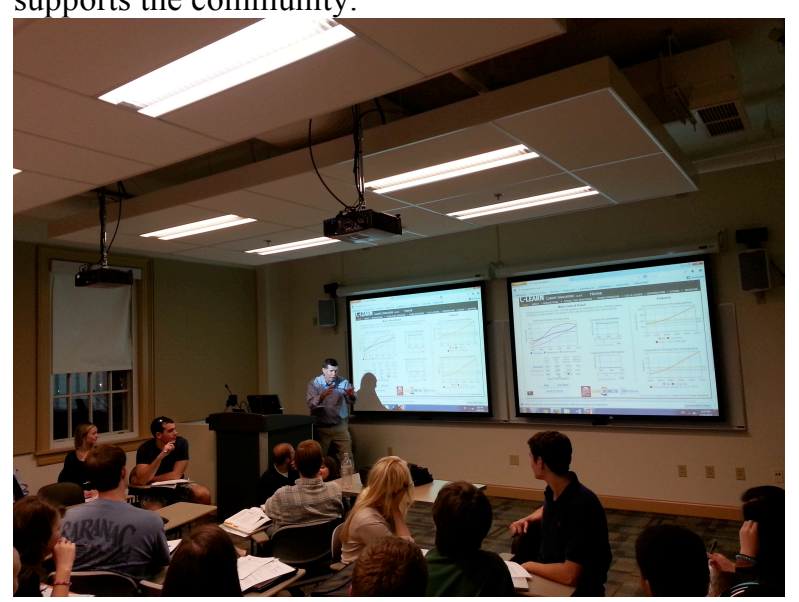

Figure 3: MPA Students learning about GDSS and Simulation Environments

Simulation experiments with CoastalProtectSIM consisted of designing and testing policy packages to reduce damages resulting from storms or floods in the pseduonymic Pointe Claire region. Participants in the simulation experiment with policy packages that may include (a) building a barrier; (b) clearing homes from the floodplain by implementing a buyout, relocation, or reclamation policy; (c) instituting a strict building code; and (d) zoning for land development. Results to assess different policy packages include accumulated damages to the city, as well as impacts on tax increases and the regional economy.

In the last two weeks of the course, participants were asked to design, as a team, a policy package suggested to the Pointe Claire community and to compose a policy memo. The size of teams varied, from four to six.

During the experiment, we found two challenges in using CoastalProtectSIM: (1) the complexity of the model and (2) making compromises between conflicting interests. The model contains over 150 variables, including a high level of feedback complexity. Some of the key state variables (such as land development) are included in more than 40 feedback loops. Moreover, the model includes a significant number of non-linear relationships. The participants had difficulties in understanding the underlying theory of the model and interpreting the simulation results to find out effective policies. Although we attempted to solve this problem by developing a user-friendly interface, there is still much to learn on how to create such interfaces for group decision support.

The second difficulty is related to finding ways of negotiating policies and reaching agreement. Even when primary factors affecting the results of the simulations are identified by team members, reaching an agreement on the policy choices among participants is a challenging task, particularly when group participants have conflicting interests (environment vs. economic development). Although the use of the simulator was acknowledged by participants as an effective tool to facilitate discussions among group members, there is a need to find better scripts to facilitate such conversations.

As a result of the experience, students that participated acquired new skills and attitudes towards emergency management and learning about complex problems. In their individual self-assessments, participants in the experiment reported a higher sense of responsibility, and a strong sense of belonging to the group. All participants reported the experience as a trust-building and team-building experience. The sense of community, team work and trust reported by participants is akin to required attributes by stakeholder networks that work together in emergency response events. Moreover, participants report that the experience helped them to improve in their abilities to 
work on teams and integrating several perspectives and abilities to problem solving and decision making. Table 1 shows the mean and standard deviations for these two scales, as well as the items included in each of them. All items in the scale used a 0-4 Likert scale, where 4 reflects a high impact of the experience on participant skills.

\section{Table 1: Preliminary Measures of the Impact of} GDSS on Emergency Management Skills

\begin{tabular}{|c|c|}
\hline Scale & Survey Items \\
\hline $\begin{array}{l}\text { Multi- } \\
\text { perspective } \\
\text { thinking } \\
\text { Mean: } 3.17 \text {; } \\
\text { SD: .67; Min: } \\
\text { 0; Max: } 4\end{array}$ & $\begin{array}{l}\text { - Understand how to coordinate different } \\
\text { perspectives of different stakeholders in } \\
\text { public policy decision making. } \\
\text { - Understand the effect of policy decisions } \\
\text { on external environment (e.g., other levels } \\
\text { of government, private and nonprofit } \\
\text { sectors, and citizens). } \\
\text { - Understand the effectiveness of working in } \\
\text { a group. } \\
\text { Be encouraged to look for new ways to } \\
\text { approach conventional policy issues (e.g., } \\
\text { protection against natural disasters, city } \\
\text { development, and public service provision). }\end{array}$ \\
\hline $\begin{array}{l}\text { Problem- } \\
\text { solving } \\
\text { competence } \\
\text { Mean: } 2.97 \text {; } \\
\text { SD: .76; Min: } \\
1 \text {; Max:4) }\end{array}$ & $\begin{array}{l}\text { - Understand how to break complex } \\
\text { problems into manageable components. } \\
\text { Understand how to gather information } \\
\text { (data) which is needed to make a public } \\
\text { policy decision. } \\
\text { Understand how to analyze information } \\
\text { (data) in order to provide scientific } \\
\text { evidence in a public policy decision- } \\
\text { making process. } \\
\text { Understand how to deal with trade-offs } \\
\text { (i.e., two or more conflicting objectives } \\
\text { or values) based on scientific evidence in } \\
\text { a public policy decision-making process. } \\
\text { Understand how to resolve policy } \\
\text { problems by considering complex } \\
\text { relationships among various factors. } \\
\text { Understand how to communicate } \\
\text { technical ideas in ordinary written } \\
\text { language. } \\
\text { Understand how to tailor information to } \\
\text { diverse audience. }\end{array}$ \\
\hline
\end{tabular}

Additionally, the class required from participants a memo presenting their analysis and recommendations. The memoranda from students suggest that they were capable to analyze a set of policy packages under a set of scenarios, and that they were using the simulation results to support their conclusions. For example, one of the teams identified three possible policy approaches: a preservationist approach, which included stricter zoning regulations and building codes and a local tax levy to offset the tax loss from stricter zoning regulations; a commercial approach, which included the construction of higher protective barriers and increased taxes in coastal development to cover the cost of the barriers; and a collaborative approach, which included building protective barriers and modifications to zoning regulations.

After the experience with the model, the team decided to choose a collaborative approach, as they expressed in their Memo: "The preferred policy package is to build 15 inch barriers and an auto tax to cover their costs, along with partial zoning regulations (a level of .5) beginning in the year 2014. It is estimated to take about 5 years to complete the planning and studies needed for the barriers, and an additional 10 years to complete the construction of the barriers." Using simulation runs, the team was able to identify main weaknesses and strengths of their policy package, for example, "the proposed seawalls and zoning regulations holds up well against low to moderate levels of global warming in several random worlds in the CoastalProtectSIM model. The policy package has a comparative low cost to homeowners, stemming from the lack of building codes." Overall, students show good understanding of the model and their policy options. In addition, the use of a simulation model provided insight into the delays and trade-offs inherent in considerations of public policy decisions.

\section{Discussion and Conclusions}

In this paper, we have illustrated the use of a GDSS (CoastalProtectSIM) as a tool to be used by managers during the mitigation and preparedness phases of the Emergency Management Cycle. Our initial results suggest that the tool is effective in supporting groups in the design and analysis of policy packages to increase community resilience. Although the GDSS in this paper relates mostly to these stages, previous literature suggests the effectiveness of GDSS in all four stages of the cycle $[6,24,28]$. Moreover, the four stages in the emergency management cycle (mitigation, preparedness, response and recovery) are closely interrelated, and activities in each phase will impact the others [9], arguing for a systems-based and feedbackdriven modeling approach. Furthermore, there are not clear boundaries between each phase.

The emergency management process does not operate in the vacuum, but it depends on many variables that are related to specific contexts, social conditions and institutional and government realities. Current efforts such as the National Incident Management System (NIMS) [4] and the National Information Exchange Model (NIEM) also suggest a connection between emergency management and the domain of GDSS.

In this way, we finish this paper by proposing a framework that attempts to integrate both concepts, EM and GDSS (Figure 4). The Emergency 
Management cycle is immersed in a complex context that involves local resource constraints, a multitude of different stakeholders with competing, sometimes conflicting goals. In this context, GDSS can provide an interactive computer-based methodology to help groups of stakeholders from the society at large and government find out appropriate solutions and better decision making along the whole process.

\subsection{Discussion}

In the wider context of the social milieu, Emergency Management is just one of the many activities that societies need to thrive and grow in a sustainable way, similar to transportation, finance, social assurance and health planning. Making any decision on EM plans or schemes, implies first careful thinking on the resources available as well as how easy would be to get a hold of them in case they are needed. On the other hand, according to the changeability of the incidents, EM planning requires the identification of key stakeholders, as well as their priorities in case of an emergency.

Goals and priorities among stakeholders, as we suggested earlier, are many times competing or even in conflict. We believe that negotiating priorities, resources and goals for Emergency Management can be improved by the introduction of GDSS in the several stages of the emergency management cycle [9]. As suggested in Figure 4, the emergency management cycle can be roughly divided in two stages, before incidents and after incidents. In each of these simplified stages, resilience can be simply defined as the ability that the city has to face incidents and respond to emergencies.

Before incidents happen, emergency managers and other stakeholders work on mitigation and preparedness. Work on these areas reflects the city's resilience. During these phases, government develops and/or reserves enough resources for potential events, including food, water, tents and other relief supplies. Resources also include shelters, which aim to minimize the effects of unavoidable emergencies. To reduce risks associated with emergency events, governments attempt to enact a series of policies to reduce the city's vulnerabilities. In the case introduced in this paper, policy packages included the construction of higher dams to protect the city from storm surges, changes in the zoning and construction codes, as well as funding strategies. Moreover, policy design is uncertain, and policy makers need to deal with a variety of futures or possible scenarios.

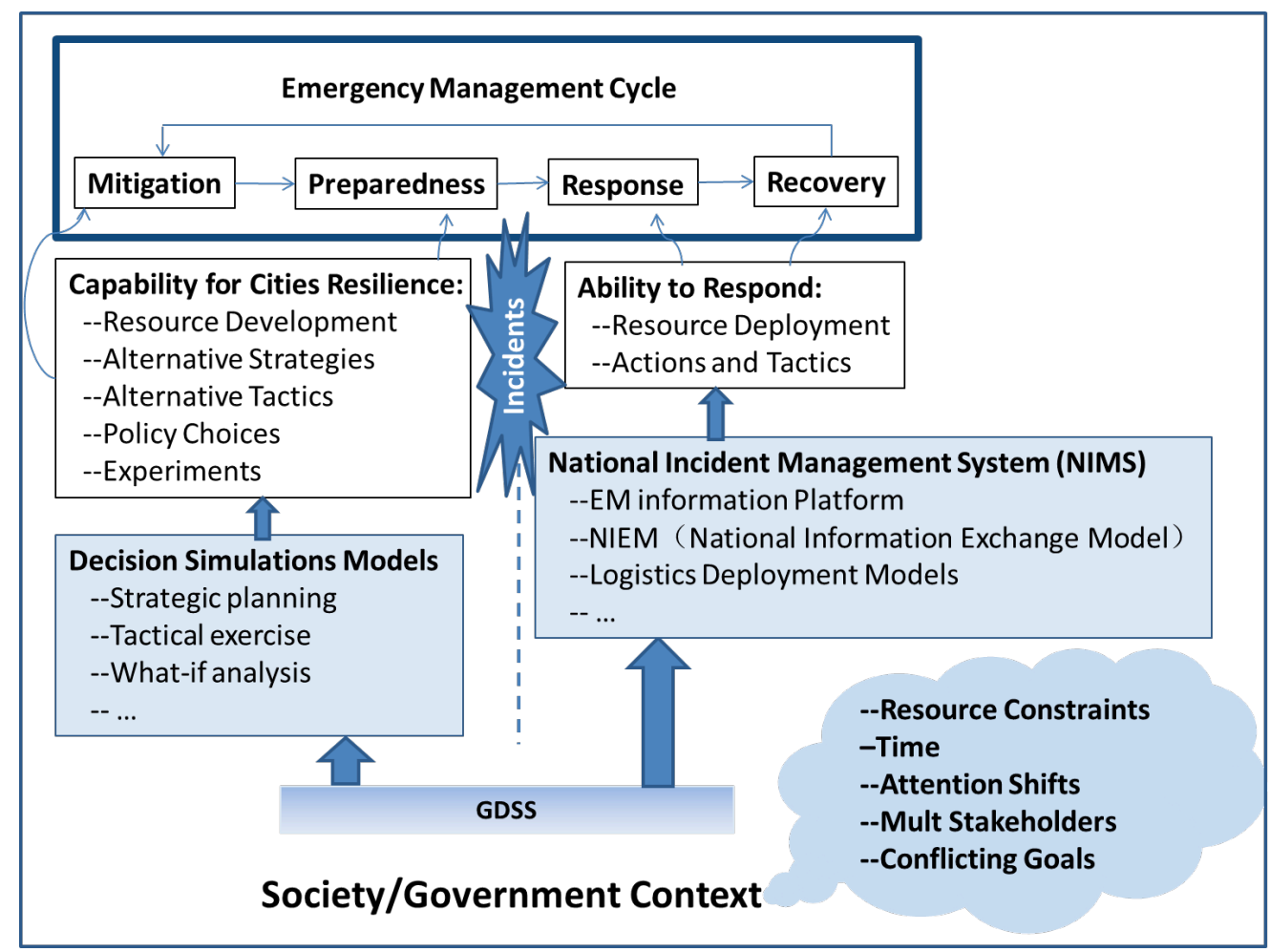

Figure 4: GDSS and the Emergency Management Cycle 
Additionally, city governments also need to develop policies and plans at the strategic and tactical levels to make sure a timely and appropriate response in the case of an emergency. Alternative strategies are provided to different kinds of incidents in different environments, and alternative tactics can help governments and the public to quickly respond when incidents happen.

As suggested in Figure 4, different GDSS models and systems need to be deployed in different stages of the emergency management cycle. Stages of mitigation and preparedness call more naturally for capability building, long term strategic models such as CoastalProtectSIM. Later stages require the development and use of more tactical and operation focused models and systems such as NIMS and NIEM. The use of models, data and computer simulations, make easy to explore policy packages under a variety of scenarios. Preferred policy packages then can be built either to prepare for the emergency events or for orchestrating emergency response and recovery. GDSS provides an organizing framework that reminds the importance of hardware, software, processes and people [11, 14, 20,24].

\subsection{Conclusion and further research}

In this paper we specifically consider waterrelated emergency events such as floods, hurricanes and storms. Our experience with CoastalProtectSIM suggest that GDSS and simulation models have the potential to help city governments to improve city's resilience by developing capabilities of data use and data models to tackle complex public policy problems. CoastalProtectSIM, together with a design of group processes and simulation experiments, provide a tool to learn about policy packages to improve preparedness for future calamities.

The experience with the Pointe Claire Coastal Protection Planning Exercise (PCCPPE) illustrates the usefulness of using simulation to better understand how changes in priorities among development, built protection and preservation interact over time and different assumptions impact economic development and actual damage in the case of the occurrence of emergency events.

With seeing the effectiveness of in-class simulation exercises in facilitating trust and team building, and improving the acknowledgement of emergency management skills, GDSS may be helpful for elevating resilience in communities through improved policies and decisions making during mitigation and preparedness stage of emergency management (the left column of Figure 4) in policy planning. We believe that using this kind of GDSS simulator may also help to facilitate exchanging ideas and policy preferences among group members and provide a tool to get immediate feedback on decision making and solution negotiation in the response and recovery stages of emergency management (the right column of Figure 4).

A limitation of the research reported here in validating the usefulness of GDSS lies in the use of self-reported measures of success. However, in this paper we are just starting to explore GDSS in waterrelated emergency management. Our future research involves experimenting in real environments, engaging actual policy makers and emergency response managers in different governmental contexts. We are planning to adapt CoastalProtectSIM to the context of China southeastern coastal cities, as well as cities in the coast of the Northeastern United States. Once the model is initially adapted to local historical data, we are looking for GDSS experiences in this environment. We expect that these experiments will contribute, on one hand, to promote strategic and systemic thinking about all states of emergency management, particularly in the mitigation and preparedness emergency management cycle. Additionally, knowledge from emergency managers and other stakeholders will yield new insights to improve city resilience through effective emergency management.

\section{Acknowledgements}

The work is partially supported by Natural Science Foundation of Guangdong Province China (Grant No. 2015A030313315), Guangdong Provincial Science and Technology Plan (Grant No. 2014A070711013) and the Fundamental Research Funds for the Central Universities (Grant No. 15JNKY002). Any opinions, findings, and conclusions or recommendations expressed in this material are those of the authors and do not necessarily reflect the views of the National Science Foundation of Guangdong, the Guangdong Provincial Science and Technology Plan, the Research Funds for the Central Universities or the US Army Corps of Engineers.

\section{References}

[1] F. Ackermann, and C. Eden, "Issues in computer and non-computer supported GDSSs", Decision Support Systems, 1994, pp. 381-390

[2] D. F. Andersen, and G. P. Richardson, "Scripts for group model building", System Dynamics Review (Wiley), 1997, pp. 107-129 
[3] R. M. Barishansky, The Word on Resilience, Emergency Management, 2015. http://www.emergencymgmt.com/disaster/The-Word-onResilience.html

[4] G.W. Bush, Homeland Security Presidential Directive/HSPD-5: Management of Domestic Incidents, 2003. https://fas.org/irp/offdocs/nspd/hspd-5.html

[5] M. Deegan, K. Stave, R. MacDonald D. Andersen, M. $\mathrm{Ku}$, and E. Rich, "Simulation-Based Learning Environments to Teach Complexity: The Missing Link in Teaching Sustainable Public Management", Systems, 2014, pp. 217-236

[6] J. Deng, and X. Chen, "The Design of Group Decision Support System for Emergency Management", 3Rd International Symposium On Electronic Commerce And Security, 2010, pp.134-139

[7] T. Drabek, Emergency Management: Principles and Practice for Local Government, International City Management Association, Washington, D.C, 1991

[8] DOJ. National Information Exchange Model (NIEM). https://www.niem.gov/aboutniem/Pages/history.aspx

[9] A. K. Donahue, and P.G. Joyce, "A framework for analyzing emergency management with an application to federal budgeting", Public Administration Review, 2001, pp. 728-740

[10] D. R. Godschalk, "Urban Hazard Mitigation: Creating Resilient Cities", Natural Hazards Review, 2003, pp. 136143

[11] P. Gray, "The Nature of Group Decision Support Systems", Handbook on Decision Support Systems, F. Burstein and C.W. Holsapple, eds., Springer, 2008, pp. 371-389

[12] R. L. Hayen, S. A. Swaby, and Z. Huang, "Use of Group Support Systems in Today's Society", Issues in Information Systems, 2007, pp. 120-126

[13] D. Henstra, "Evaluating Local Government Emergency Management Programs: What Framework Should Public Managers Adopt?" Public Administration Review, 2010,pp. 236-246

[14] G. P. Huber, "Issues in the Design of Group Decision Support Systems", MIS Quarterly, 1984, pp. 195204

[15] M. Janža, "A decision support system for emergency response to groundwater resource pollution in an urban area (Ljubljana, Slovenia)", Environmental Earth Sciences, 2014

[16] M. Ku, R. MacDonald, D. L. Andersen, D. F. Andersen, and M. Deegan, "Teaching and Learning about Complexity in Public Policy Decision Making: Using a Simulation-Based Learning Environment in the MPA
Classroom", Journal of Public Affairs Education, 2016, pp. 49-66

[17] A. Liu, Post-Katrina New Orleans is bouncing back, but not for the better, The Avenue: Rethinking Metropolitan America, Brookings Institution, 2015. http://www.brookings.edu/blogs/the avenue/posts/2015/08/26-post-katrina-new-orleans-liu.

[18] L. F. Luna-Reyes, "Trust and Collaboration in Interorganizational Information Technology Projects in the Public Sector", Gestión y Política Pública, 2013, pp. 173211

[19] D. Mileti, Disasters by Design: A Reassessment of Natural Hazards in the United States, Joseph Henry Press, 1999

[20] R. G. Milter, and J. Rohrbaugh, "Microcomputers and Strategic Decision Making", Public Productivity Review, 1985, pp. 175-189

[21] J. F. Nunamaker Jr, "Experience with and future challenges in GDSS (group decision support systems): Preface", Decision Support Systems, 1989, pp. 115-118

[22] A. L. Plough, and A. Chandra, What Hurricane Katrina Taught Us About Community Resilience, The RAND Blog, 2015. http://www.rand .org/blog/2015/09/what-hurricane-katrinataught-us-about-community-resilience.html

[23] G. P. Richardson, and D. F. Andersen, "Teamwork in group model building", System Dynamics Review (Wiley), 1995, pp. 113-137

[24] J. Rohrbaugh, "Cognitive challenges and collective accomplishments", In R. Bostrom and S.T. Kinney, eds., Computer augmented teamwork: A guided tour, Van Nostrand Reinhold, New York, NY, 1992, pp. 299-324

[25] L. Steinberg, N. Santella, and C. Zoli, "Baton Rouge Post-Katrina: The Role of Critical Infrastructure Modeling in Promoting Resilience", Homeland Security Affairs, 2011 [26] S. Vangen, and C. Huxham, "Nurturing Collaborative Relations: Building Trust in Interorganizational Collaboration", The Journal of Applied Behavioral Science, 2003, pp. 5-31

[27] J. A. M. Vennix, D. F. Andersen, G. P. Richardson, and J. Rohrbaugh, "Model building for group decision support: Issues and alternatives in Knowledge elicitation", Modeling for Learning Organizations, Productivity Press, Portland, OR, 1994

[28] L. Yu, and K. K. Lai, "A distance-based group decision-making methodology for multi-person multicriteria emergency decision support", Decision Support Systems, 2011, pp. 307-315 